\title{
INDIVIDUAL'S INTENTION TO SUBSCRIBE TO FREEMIUM MUSIC STREAMING SERVICES: A CONCEPTUAL FRAMEWORK
}

\author{
Norshidah Mohamed ${ }^{1}$ and Hanif Haghshenas ${ }^{2}$ \\ ${ }^{1}$ College of Business Administration, Prince Sultan University, P.O. Box 53073 Riyadh 11586, Kingdom of Saudi Arabia. \\ ${ }^{2}$ Azman Hashim International Business School, Universiti Teknologi Malaysia, Jalan Sultan Yahya Petra, 54100 Kuala \\ Lumpur, Malaysia
}

\begin{abstract}
While the music industry continues to undergo through significant revolution, the last few years show that growth in freemium music streaming services continue to be noteworthy, in particular, in the American music industry. The research aspires to gain insights into individual's intention to subscribe to freemium music streaming services. This paper reports a research in progress. The research integrates the Theory of Reasoned Action, Dual Mediation Hypothesis, Motivation Theory, and Social Identity Theory to develop a conceptual framework toward explaining individual's intention to subscribe to freemium music streaming services.
\end{abstract}

\section{KEYWORDS}

Music Streaming, Freemium Music, Free Music, Purchase Intention, Attitude

\section{INTRODUCTION}

The Internet has brought about innovation that spans many information technological advances. It has shaped many industries. The music industry is one example that has experienced phenomenal transformation as a result of the Internet. To date, the industry is still going through a revolution. Despite notable music piracy issues, the Recording Industry Association of America recently reported that the American music industry's 2019 retail revenue was about $\$ 11.1$ billion. This is an increase from $\$ 9.8$ billion in 2018 and $\$ 8.8$ billion in 2017. Streaming consumption surged from 75 percent in 2018 to 79 percent in 2019.

The notion of offering individuals with free music streaming services stems from the need of the industry to curtail music piracy, lowered sales attributable to piracy and decreased music rights holder revenue (Aguiar, 2017). Freemium business model is grounded on offering consumers with basic services as providers earn their revenue through advertisements. This is in anticipation that over time consumers will develop needs for advanced features and therefore turn to freemium services (Wagner et al. 2014).

While explaining digital music purchase intention, researchers in the past, have focused on determinants such as unauthorized downloading (Hampton-Sosa, 2017) and attitudes toward digital music services (Dörr et al. 2013; Wagner et al. 2014; Fernandes, T. Guerra, 2019). Anecdotal evidence shows that among theories that have been adopted in digital music services research include Theory of Planned Behavior (Dörr et al., 2013). Dual Mediation Hypothesis, (Wagner et al. 2014), and Technology Acceptance Model (Hampton-Sosa, 2017).

This research is different from past researches in that it builds on and integrates the Theory of Reasoned Action, Dual Mediation Hypothesis, Motivation Theory, and Social Identity Theory, to explain individual's intention to stream free music. The research significantly contributes to the literature through development of this new framework. From practical contributions standpoint, findings can aid music service provider in shaping their services to encourage potential subscription and discourage piracy. Hence, the research question sets out in this research: What are the determinants of individual's intention to subscribe to freemium music streaming services? 
This paper is organized into four sections. This section has introduced the research area. Section two discusses the literature review and related theories. The third section the paper presents the research propositions and conceptual framework. The last section concludes the paper.

\section{LITERATURE REVIEW AND RELATED THEORIES}

\subsection{Theory of Reasoned Action}

The Theory of Reasoned Action (TRA) (Fishbein \& Ajzen, 1975; Ajzen \& Fishbein, 1980) has been used to explain individual's behavior. The TRA (Figure 1) has been widely applied in various researches. More recently, it is evident in green IT (Mishra et. al. 2014) and water conservation for a lodging study (Untaru, 2016). Accordingly, the theory specifies that intention induces individual's behavior while his/her attitudes (affective reaction) and subjective norms determine the intention.

Subjective norm refers to an individual's perception of what his/her referent think he/she should engage in a behavior (Ajzen, 1991; Fishbein and Ajzen, 1975). Subjective norms have been theorized in several behavioral models from cognitive psychology including TRA (Fishbein and Ajzen, 1975) and the Theory of Planned Behaviour (TPB) in Ajzen (1991).

The phenomenon of interest in the present research is individual's intention to stream freemium music. In freemium music, individuals pay subscription to enjoy additional features of the music. In free music, individuals enjoy basic services with advertisements. The research proposes that the intention to stream freemium music is dependent on individual's attitude to stream free music and freemium music; free services is a precursor to freemium.

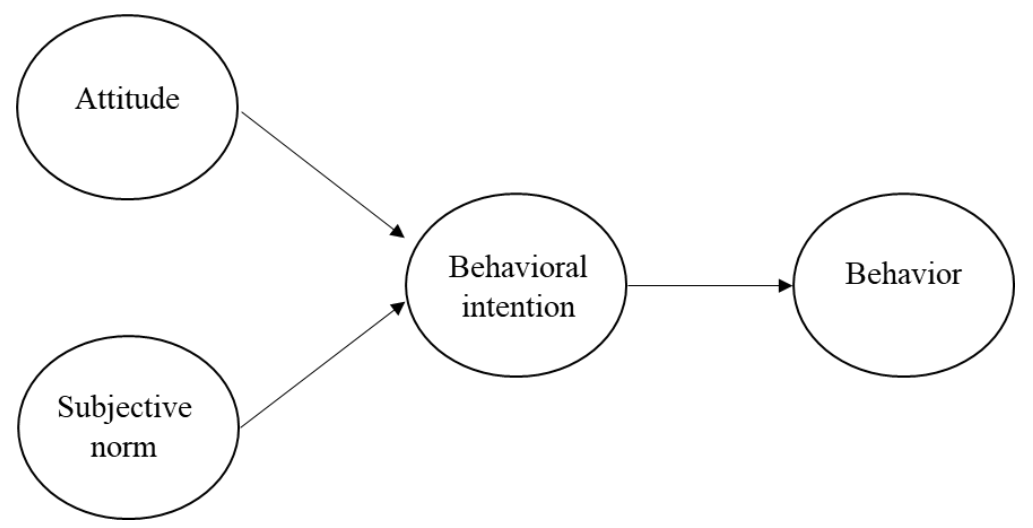

Figure 1. Theory of Reasoned Action

\subsection{Dual Mediation Hypothesis Theory}

The Dual Mediation Hypothesis (DMH) theory is traced to advertising literature (MacKenzie, Lutz, and Belch, 1986). The theory suggests a direct and indirect influence of attitude toward advertisement $\left(\mathrm{A}_{\mathrm{ad}}\right)$ on attitude toward brand $\left(\mathrm{A}_{\mathrm{b}}\right)$. The indirect influence is through brand cognition $\left(\mathrm{C}_{\mathrm{b}}\right.$ or perception). Further, attitude toward advertisement has indirect influence on purchase intentions (PI) through attitude toward brand.

Notably, the DMH has been used in investigating return to a website (Karson and Fisher, 2005a), online advertisement (Karson and Fisher, 2005b), website effectiveness (López and Ruiz, 2011), and purchase and use of games (Davis et al. 2013). Figure 2 shows the conceptual framework of the DMH. 


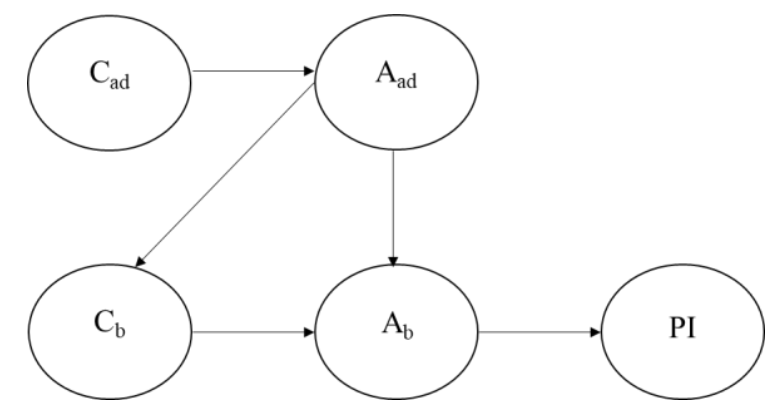

Figure 2. Dual Mediation Hypothesis

\subsection{Motivation Theory}

The present research builds on the hedonic motivation and utilitarian motivation theories. These theories are discussed further in this section.

Hedonic motivation is defined by Holbrook (1994) as intrinsic value which is derived from "appreciation of an experience for its own sake, apart from any other consequence that may result". Hedonic information systems concern leisure activities and fun aspect about the use. The context of hedonic information systems is home and personal rather than organization and job context (van der Heijden, 2004). Accordingly, in attaining a pleasurable experience, individuals often seek sensations on multiple sensory channels (Holbrook and Hirschman 1982). Therefore, hedonic motivation relates to sound, color, aesthetically appeal, visual layout, animated images etc.

This definition is not similar to perceived usefulness which is commonly identified as "the degree to which a person believes that using a particular system would enhance his or her job performance" (Davis, 1989). Hedonic motivation is also different from task completion concept because fun and playfulness are personal and subjective sources of perception about an intrinsic value (Babin, 1994). Hedonic motivation relates to psychological or emotional values (affective features of technology or intrinsic values).

Utilitarian motivation is formed as value, believed to be a driver of consumer's choice and preferences (Chiu et al., 2005). Value was initially and dominantly considered as unidimensional and economic-based consumer utilitarianism. Value in this regard was defined as a cognitive trade-off between benefits or performance (quality) and sacrifices as costs (or price) (Zeithaml, 1988). Mathwick et al. (2001) further divided utilitarian or extrinsic values into two dimensions: (i) efficiency/customer ROI (extrinsic-active value) and (ii) excellent/quality appeal (extrinsic -reactive value). This conceptualization has been confirmed in the context of online book and CD retailing (Wetzels, et al., 2009). Excellence was defined as service excellence and customer return on investment (ROI) were conceptualized as efficiency and economic values. In the context of mobile games, efficiency (convenience) of a game has been captured through communication characteristics such as game speed and accessibility, while the quality of a game has been captured through attractive characteristics such as sound quality, goal setting, and game options (Kim, et al., 2010).

In recent years, the application of hedonic and utilitarian motivation is evident in shopping goals (Chiu, et al., 2014) and in a shopping website López and Ruiz (2011).

\subsection{Social Identity Theory}

Social Identity Theory (SIT) suggests that individuals emphasize more on a shared social identity rather than a personal identity (O'Fallon and Butterfield, 2012). Individuals identify themselves in relation to their social groups in projecting a positive social identity (e.g. Tajfel, 1978; Tajfel and Turner, 1985).

SIT could also be specified as perceived fit with group identity (O'Fallon and Butterfield, 2012). SIT has been applied in fashion patronage behavior; people who keep up with fashion follow herding behavior (Evans, 1964; Gurel et al., 1972) and are prone to peer influence (McKintyre and Miller, 1992). More recently, SIT is evident in in application of digital data about veganism (Davis et al. 2019) and among online gamers (Liao, 2020). This research posits that individuals identify themselves with the image consistent with the group they belong to in regard to streaming music. 


\section{PROPOSITIONS AND CONCEPTUAL FRAMEWORK}

Against this backdrop, the present research proposes that individual's attitude toward free music services is determined by cognition about free music. This comprises the hedonic, utilitarian and social identity factors. Subjective norm is also proposed to determine attitude toward free music services. Consequently, individual's attitude toward free music services and brand cognition about freemium services are posited to determine attitude toward freemium music services. However, this brand cognition is proposed to be determined by the brand price value. Individual's attitude toward freemium service determines the intention to purchase the services.

Thus, we postulate the following propositions and conceptual framework (Figure 3) in determining individual's intention to subscribe to freemium music services:

P1: Individual's attitude toward freemium music services is positively and significantly correlated to intention to subscribe to freemium music services.

P2: Individual's attitude toward free music services is positively and significantly correlated to attitude toward freemium music services.

P3: Individual's cognition about freemium music services is positively and significantly correlated to attitude toward freemium music services.

P4: Individual's perceived price value is positively and significantly correlated to freemium music services.

P5: Individual's need for escapism is positively and significantly correlated to his attitude toward free music services.

P6: Individual's need for enjoyment is positively and significantly correlated to his attitude toward free music services.

P7: Individual's need for entertainment is positively and significantly correlated to his attitude toward free music services.

P8: Individual's need for safe music streaming services is positively and significantly correlated to his attitude toward free music services.

P9: Individual's need for quality sound of music streaming services is positively and significantly correlated to his attitude toward free music services.

P10: Individual's need for accessible of streaming music services is positively and significantly correlated to his attitude toward free music services.

P11: Individual's subjective norm is positively and significantly correlated to his attitude toward free music services.

P12: Individual's need for perceived fit with his group is positively and significantly correlated to his attitude toward free music services.

\section{CONCLUSION}

The music industry continues to undergo through significant revolution. Despite this phenomenon, the American music industry, in particular, exhibits growth in freemium music streaming services over the last few years. The research aspires to gain insights into individual's intention to subscribe to freemium music streaming services. It aims at making a significant theoretical contribution to knowledge and practical contribution to knowledge application. This paper reports a research in progress. It demonstrates the integration of the Theory of Reasoned Action, Dual Mediation Hypothesis, Motivation Theory, and Social Identity Theory to develop a conceptual framework toward explaining individual's intention to subscribe to freemium music streaming services. The research aspires to make significant theoretical contributions by the development and testing of a model that explains individual's intention to subscribe to freemium music streaming services. From practical contribution standpoint, the research anticipates that findings could offer guidelines in aligning administrative and business policies to factors that determine intention to subscribe to freemium music streaming services.

The next stage of the framework is developing and testing a theoretical model toward operationalizing the constructs. Plans are underway to collect data using online survey questionnaire. Data are planned to be analyzed using structural equation model. 


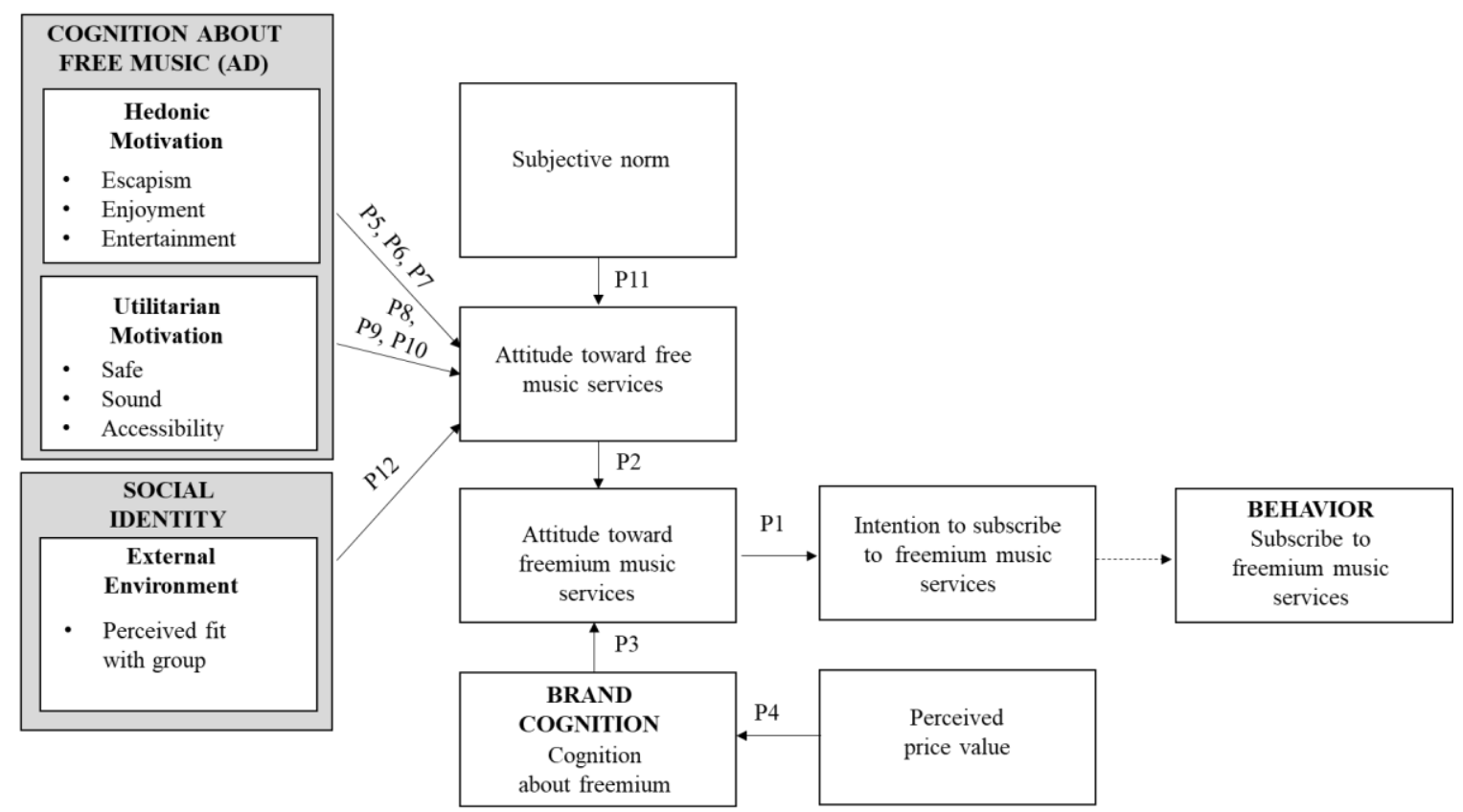

Figure 3. Conceptual Framework

\section{REFERENCES}

Aguiar, L. 2017. Let the music play? Free streaming and its effects on digital music consumption. Information Economics and Policy, Vol. 41, pp. 1-14.

Ajzen, I. and Fishbein, M. 1980. Understanding Attitudes and Predicting Social Behavior. Prentice-Hall, Englewood Cliffs, NJ.

Babin, B. J., Darden, W. R. and Griffin, M. 1994. Work and/or fun: measuring hedonic and utilitarian shopping value. Journal of Consumer Research, Vol. 20, No. 4, pp. 644-656.

Chiu, H.-C., Hsieh, Y.-C., Li, Y.-C. and Lee, M. (2005). Relationship Marketing and Consumer Switching Behavior. Journal of Business Research, Vol. 58, No. 12, pp. 1681-1689.

Davis, F. D. 1989. Perceived usefulness, perceived ease of use, and user acceptance of information technology. MIS Quarterly, Vol. 13, No. 3, pp. 319-339.

Davis, R. Lang, B. and Gautam, N. 2013. Modeling utilitarian-hedonic dual mediation (UHDM) in the purchase and use of games. Internet Research, Vol. 23, No. 2, pp. 229-256.

Davis, J. L., Love, T. P. and Phoenicia Fares, P. 2019. Collective social identity: Synthesizing identity theory and social identity theory using digital data. Social Psychology Quarterly, Vol. 00, No. 0, pp. 1-20.

Dörr, J., W., Benlian, T. M., A. and Hess, T. 2013. Music as a service: an alternative to music piracy? An empirical investigation of the intention to use music streaming services. Business \& Information Systems Engineering, Vol. 5, No. 6, pp. 383-396.

Evans, S. E. 1964. Motivations underlying clothing selection and wearing. Journal of Home Economics, Vol. 56, September, pp. 739-743.

Fernandes, T. Guerra, J. 2019. Drivers and deterrents of music streaming services purchase intention, International Journal of Electronic Business, Vol.15, No. 1, pp.21 - 42.

Fishbein, M. and Ajzen, I. 1975. Belief, Attitude, Intention and Behavior: An Introduction to Theory and Research. Addison-Wesley, Reading, MA.

Gurel, L.M., Wilbur, J.C. and Gurel, L. 1972. Personality correlates of adolescent clothing styles. Journal of Home Economics, Vol. 64, No. 3, pp. 42-47.

Hampton-Sosa, W. 2017. An exploration of essential factors that influence music streaming adoption and the intention to engage in digital piracy. International Journal of Electronic Commerce Studies, Vol. 8, No.1, pp. 97-134. 
Holbrook, M. B. 1994. The nature of customer value: An axiology of services in the consumption experience. In Rust, R. T. and Oliver, R. L. (ed.), Service Quality: New Directions in Theory and Practice, Thousand Oaks, California, pp. 21-71.

Holbrook, M. B., and Hirschman, E. C. 1982. The experiential aspects of consumption: consumer fantasies, feelings, and fun. Journal of Consumer Research, Vol. 9, No. 2, pp. 132-140.

Karson, E. J. and Fisher, R. J. 2005a. Predicting intentions to return to the web site: extending the dual mediation hypothesis. Journal of Interactive Marketing, Vol. 19, No. 3, pp. 2-14.

Karson, E. J. and Fisher, R. J. 2005b. Reexamining and extending the dual mediation hypothesis in an on-line advertising context, Psychology \& Marketing, Vol. 22, No. 4, pp. 333-351.

Kim, C-S., Oh, E-H., Yang, K. H. and Kim, J. K. 2010. The appealing characteristics of download type mobile games. Service Business, Vol. 4, No. 3-4, pp. 253-269.

Liao, G-Y., Pham, T.T. L., Cheng, T.C.E., Ching-I Teng, C-I. 2020. How online gamers' participation fosters their team commitment: Perspective of social identity theory. International Journal of Information Management, Vol. 52, pp. 1-12.

López, I. and Ruiz, S. 2011. Explaining website effectiveness: The hedonic-utilitarian dual mediation hypothesis. Electronic Commerce Research and Applications, Vo. 10, pp. 49-58.

Mathwick, C., Malhotra, N. and Rigdon, E. 2001. Experiential value: conceptualization, measurement and application in the catalog and Internet shopping environment. Journal of Retailing, Vol. 77, No. 1, pp. 39-56.

MacKenzie, S. B., Lutz, R. J., and Belch, G. E. 1986. The role of attitude toward the ad as a mediator of advertising effectiveness: A test of competing explanations. Journal of Marketing Research, Vol. 13, pp. 130-143.

McKintyre, S.H. and Miller, M. C. 1992. Social utility and fashion behavior. Marketing Letters, Vol. 3, No. 4, pp. 371-382.

Mishra, D., Akman, I and Mishra, A. 2014. Theory of Reasoned Action application for Green Information Technology. Computers in Human Behavior, Vol. 36, pp. 29-40.

O'Fallon, M. J. and Butterfield, K. D. 2012. The influence of unethical peer behavior on observers' unethical behavior: A social cognitive perspective. Journal of Business Ethics, Vol. 109, No. 2, pp. 117-131.

Tajfel. H. (1978) The achievement of group differentiation. In Differentiation Between Social Groups: Studies in the Social Psychology of Intergroup Relations, Tajfel, H. (ed.), Academic Press, London, pp. 77-98.

Tajfel, H. and J.C. Turner, J. C. 1985. The social identity theory of intergroup behavior, in Psychology of Intergroup Relations, Worchel S. and Austin, W.G. (ed), Nelson Hall, Chicago, pp. 7-24.

Untaru, E-N., Ispas, A., Candrea, A. N., Marcela Luca and M. Epuran, G. 2016. Predictors of individuals' intention to conserve water in a lodging context: the application of an extended Theory of Reasoned Action. International Journal of Hospitality Management, Vol. 59, pp. 50-59.

van der Heijden, H. 2004. User acceptance of hedonic information systems. MIS Quarterly, Vol. 28, No. 4, pp. 695-703.

Wagner, T. M., Benlian, A. and Hess, T. 2014. Converting freemium customers from free to premium-the role of the perceived premium fit in the case of music as a service. Electronic Markets, Vol. 24, pp. 259-268.

Wetzels, M., Odekerken-Schroder, G. and Van Oppen, C. 2009. Using PLS path modeling for assessing hierarchical construct models: guidelines and empirical illustration. MIS Quarterly, Vol, 33, No. 1, pp. 177-195.

Zeithaml, V. A. 1988. Consumer perceptions of price, quality, and value: A means-end model and synthesis of evidence. Journal of Marketing, Vol. 52, No. 3, pp. 2-22. 